\title{
ANALISIS PENGARUH NET PROFIT MARGIN (NPM) RETURN ON EQUITY (ROE) DAN EARNING PER SHARE (EPS) TERHADAP HARGA SAHAM
}

\author{
Muhamad Jusmansyah \\ Fakultas Ekonomi, Universitas Budi Luhur Jakarta \\ jusmansyah61@gmail.com
}

\begin{abstract}
This study aims to analyze the effect of Net Profit Margin, Return on Equity and Earning Per Share on Stock Price of manufacturing companies listed on Indonesia Stock Exchange in observation year 2012 - 2016. Using a linear regression analysis method is assisted with the use of the SPSS program version 23 which utilizes secondary data from a sample of 15 (fifteen) chemical industry sector group manufacturing companies that have been listed on the Indonesia Stock Exchange for the 2012 to year period 2016. While the sampling method used is purposive sampling method. This study obtained the following results: (1) Net Profit Margin influential on Stock Price, (2) Return On Equity effect on Stock Price, (3) Earning Per Share effect on Stock Price, (4) ) The results of regression analysis simultaneously influenced the result that Earning Per Share effect on Stock Price. As for Net Profit Margin and Return on Equity does not affect the stock price.
\end{abstract}

Keywords: NPM, ROE, EPS, on Stock Price.

\section{PENDAHULUAN}

Perusahaan dapat digambarkan baik secara statis maupun secara dinamis. Secara statis, pada setiap saat suatu perusahaan dapat dilihat dari laporan keuangan (Neraca, Laporan Laba/Rugi dan Laba ditahan) untuk mengetahui kinerja Profitabilitas, Liquiditas, Solvabilitas dan Turn Over.

Stabilitas fluktuasi ekonomi atau business cycle membutuhkan kebijakan ekonomi makro baik kebijakan fiskal maupun kebijakan moneter yang tepat. Para investor memiliki minat untuk berpartisipasi dalam memiliki saham Perusahaan manufaktur yang banyak dimanfaatkan oleh para emiten yang telah mengetahui pangsa pasar modal yang ada di Bursa Efek Indoneisa. Pada Tabel 1 berikut data mengenai harga saham dari perusahaan yang termasuk sub sektor Industri Kimia dan Keramik, Gelas, Porcelen. 
Tabel 1

Fluktuasi Harga Saham Tahun 2012 - 2016

Perusahaan Industri Dasar dan Kimia

\begin{tabular}{|c|c|c|c|c|c|c|c|c|c|c|c|c|c|c|c|c|}
\hline \multirow{2}{*}{ No } & \multirow{2}{*}{$\begin{array}{c}\text { Nama } \\
\text { Perusahaan }\end{array}$} & \multicolumn{3}{|c|}{ Tahun } & \multicolumn{3}{|c|}{ Tahun } & \multicolumn{3}{|c|}{ Tahun } & \multicolumn{3}{|c|}{ Tahun } & \multicolumn{3}{|c|}{ Tahun } \\
\hline & & 2011 & 2012 & $\begin{array}{c}\text { Fluktu } \\
\text { asi }\end{array}$ & 2012 & 2013 & $\begin{array}{c}\text { Flukt } \\
\text { uasi }\end{array}$ & 2013 & 2014 & $\begin{array}{c}\text { Fluktu } \\
\text { asi }\end{array}$ & 2014 & 2015 & $\begin{array}{c}\text { Flukt } \\
\text { uasi }\end{array}$ & 2015 & 2016 & $\begin{array}{c}\text { Flukt } \\
\text { uasi }\end{array}$ \\
\hline 1. & $\begin{array}{l}\text { PT Barito } \\
\text { Pacific } \\
\text { Tbk.(OB8.F) }\end{array}$ & 770 & 410 & $47 \%$ & 410 & 410 & $0 \%$ & 410 & 303 & $26 \%$ & 303 & 222 & $27 \%$ & 222 & 225 & $1 \%$ \\
\hline 2. & $\begin{array}{l}\text { PT Budi Starch } \\
\text { \& Sweetener } \\
\text { Tbk. (BUA.SG) }\end{array}$ & 240 & 114 & $53 \%$ & 114 & 109 & $4 \%$ & 109 & 107 & $2 \%$ & 107 & 85 & $21 \%$ & 85 & 93 & $9 \%$ \\
\hline 3. & $\begin{array}{l}\text { PT Duta Pertiwi } \\
\text { Nusantara Tbk. } \\
\text { (DPNS.JK) }\end{array}$ & 619 & 336 & $46 \%$ & 336 & 424 & $-26 \%$ & 424 & 334 & $21 \%$ & 334 & 345 & $-3 \%$ & 345 & 343 & $-1 \%$ \\
\hline 4. & $\begin{array}{l}\text { PT Ekadharma } \\
\text { Int'1 Tbk } \\
\text { (EKAD.JK) }\end{array}$ & 252 & 327 & $-30 \%$ & 327 & 366 & $-12 \%$ & 366 & 495 & $-35 \%$ & 495 & 415 & $16 \%$ & 415 & 405 & $-2 \%$ \\
\hline 5. & $\begin{array}{l}\text { PT Eterindo WT } \\
\text { Tbk. } \\
\text { (ETWA.JK) }\end{array}$ & 428 & 303 & $29 \%$ & 303 & 363 & $-20 \%$ & 363 & 260 & $28 \%$ & 260 & 165 & $37 \%$ & 165 & 175 & $6 \%$ \\
\hline 6. & $\begin{array}{l}\text { PT Intan Wijaya } \\
\text { Int'1 Tbk } \\
\text { (INCI.JK) }\end{array}$ & 203 & 237 & $-17 \%$ & 237 & 232 & $2 \%$ & 232 & 230 & $1 \%$ & 230 & 310 & $-35 \%$ & 310 & 305 & $-2 \%$ \\
\hline 7. & $\begin{array}{l}\text { PT Sorini Agro } \\
\text { A Corp Tbk, } \\
\text { (SOBI.JK) }\end{array}$ & 2,26 & 2,6 & $-15 \%$ & 806 & 1,84 & $100 \%$ & 1,84 & 2,49 & $-35 \%$ & 2,49 & 5 & $\begin{array}{c}- \\
101 \\
\%\end{array}$ & 5 & 4,89 & $-2 \%$ \\
\hline 8. & $\begin{array}{l}\text { PT Indo } \\
\text { Acidatama Tbk, } \\
\text { (SRSN.JK) }\end{array}$ & 54 & 50 & $7 \%$ & 50 & 50 & $0 \%$ & 50 & 50 & $0 \%$ & 50 & 50 & $0 \%$ & 50 & 50 & $0 \%$ \\
\hline 9. & $\begin{array}{l}\text { PT Chandra Asri } \\
\text { Petro Tbk } \\
\text { (PTCAY) }\end{array}$ & 2,8 & 4,72 & $-68 \%$ & 4,72 & 2,98 & $37 \%$ & 2,98 & 3 & $-1 \%$ & 3 & 4 & $-33 \%$ & 4 & 3,7 & $-8 \%$ \\
\hline 10. & $\begin{array}{l}\text { PT Unggul } \\
\text { Indah C Tbk. } \\
\text { (UNIC.JK) }\end{array}$ & 2000 & 1910 & $5 \%$ & 2.000 & $\begin{array}{c}1.91 \\
0\end{array}$ & $5 \%$ & 1.910 & $\begin{array}{c}1.60 \\
0\end{array}$ & $16 \%$ & 1600 & 1685 & $-5 \%$ & 1685 & 1650 & $-2 \%$ \\
\hline 11. & $\begin{array}{l}\text { PT Asahimas } \\
\text { FG Tbk, } \\
\text { (AMFG) }\end{array}$ & 6.550 & 8.300 & $-27 \%$ & 8.300 & $\begin{array}{c}7.00 \\
0\end{array}$ & $16 \%$ & 7.000 & $\begin{array}{c}8.05 \\
0\end{array}$ & $-15 \%$ & 8.050 & 7.075 & $12 \%$ & $\begin{array}{c}7.07 \\
5\end{array}$ & $\begin{array}{c}7.50 \\
0\end{array}$ & $6 \%$ \\
\hline 12 & $\begin{array}{l}\text { PT Arwana } \\
\text { Citra M Tbk, } \\
\text { (ARNA) } \\
\end{array}$ & 91 & 410 & $351 \%$ & 410 & 820 & $100 \%$ & 820 & 870 & $-6 \%$ & 870 & 560 & $36 \%$ & 560 & 575 & $3 \%$ \\
\hline 13 & $\begin{array}{l}\text { PT Intikeramik } \\
\text { Alamsari Ind } \\
\text { TBK (IKAI) }\end{array}$ & 142 & 142 & $0 \%$ & 142 & 140 & $1 \%$ & 140 & 118 & $16 \%$ & 118 & 104 & $12 \%$ & 104 & 105 & $1 \%$ \\
\hline 14 & $\begin{array}{l}\text { PT Keramika } \\
\text { Ind Ass Tbk } \\
\text { (KIAS) }\end{array}$ & 75 & 175 & $133 \%$ & 175 & 155 & $11 \%$ & 155 & 147 & $5 \%$ & 147 & 107 & $27 \%$ & 107 & 105 & $-2 \%$ \\
\hline 15 & $\begin{array}{l}\text { PT Mulia Indust } \\
\text { Tbk (MLIA) }\end{array}$ & 445 & 235 & $47 \%$ & 235 & 425 & $-81 \%$ & 425 & 525 & $-24 \%$ & 525 & 635 & $-21 \%$ & 635 & 645 & $2 \%$ \\
\hline 16 & $\begin{array}{ll}\text { PT Surya } & \text { Toto } \\
\text { Indo } & \text { Tbk. } \\
\text { (TOTO) } & \end{array}$ & 2.493 & 3.315 & $-33 \%$ & 3.315 & $\begin{array}{c}3.83 \\
9\end{array}$ & $-16 \%$ & 3.839 & $\begin{array}{c}3.96 \\
3\end{array}$ & $-3 \%$ & 3.963 & 4.825 & $-22 \%$ & $\begin{array}{c}4.82 \\
5\end{array}$ & $\begin{array}{c}4.80 \\
5\end{array}$ & $0 \%$ \\
\hline
\end{tabular}

Dari gambar Tabel 1 tersebut dapat dilihat pergerakan harga saham 15 perusahaan kelompok industri dasar dan kimia pada tahun 2016. 


\section{TELAAH LITERATUR DAN PENGEMBANGAN HIPOTESIS}

Teori persinyalan (signaling theory) mengedepankan pada arti penting dari informasi yang diperlukan oleh pemilik dana surplus untuk memutuskan investasi. Informasi ini penting untuk disampaikan kepada para investor karena informasi yang disampaikan memberikan catatan atau gambaran dan keterangan kinerja yang disesuaikan dengan kondisi pasar baik di Bursa Efek Indonenesia maupun di Pasar Modal International, agar investor dapat mengambil keputusan yang tepat.

\section{Saham}

Pengertian saham yang berlaku dan pengertian umum secara teori yang disampaikan kepada akademisi , menurut Fahmi Irham (2013)

a. Bukti kepemilikan modal.

b. Tercantum nilai kepemilikan perusahaan sesuai dengan hak dan kewajibannya.

c. Persediaan yang siap untuk dijual

Berdasarkan fungsi dan tujuannya maka harga saham dapat dipisah terdiri dari 3 macam saham yaitu:

a. Par Value (Harga Nominal).

b. Base Price (Harga Dasar)

c. Market Price (Harga Pasar)

Nilai Pasar = Harga Pasar X Total Saham yang beredar

\section{Jenis Saham}

Pengertian macam saham menurut Rusdin (2008) berlandaskan atas cara perpindahan pemiliki saham dapat dipisahkan atas dua yaitu saham atas unjuk dan saham atas nama.

Pengertian jenis saham berdasarkan kegunaan pemegang saham, menurut Rusdin (2008) yaitu:

a. Saham Biasa (Common Stock), adalah saham biasa yang dimiliki masyarakat dan juga merupakan jenis yang paling populer di pasar modal. Saham biasa dibedakan menjadi beberapa jenis (Blue Chip Stock, Income 
Stock, Blue Chip Stoc, Income Stock. Growth Stock.Cyclical Stock. Defensive Stock)

b. Speculatif Stock. Saham Preferen (Preferen Stock), jenis saham ini sering disebut sekuritas campuran yang terdiri dari:

a. Commulative Preferred Stock.

b. Non Commulative Preffered Stock.

c. Participating Preffered Stock.

\section{Harga Saham}

Pengertian Harga Saham, menurut Jogiyanto (2012): "Pasar modal akan menentukan berapa nilai saham sesuai dengan penawaran dan permintaan peminat saham. Sehubungan dikonversikan terlebih dahulu diproses pada logaritma (Log) setelah keluar angka tersebut digunakan dalam pemodelan regresi agar menyamakan harga saham yang menjadi skala rasio.

Indeks Harga Saham, menurut S. Harjadi (2003): "Suatu indikator yang menunjukkan pergerakan harga saham. Dan indeks berfungsi sebagai indicator trend pasar.

HargaSaham $=\frac{\text { jumlah harga saham penutup setiap bulan }}{12 \text { bulan }}$

Sumber: Zubir (2011:4)

\section{Profitabilitas}

Menurut Kasmir (2014) profitabilitas adalah gambaran kemampuan perusahaan dalam memperoleh memperoleh laba. Dengan rumus sebagai berikut :

$$
\text { Net Profit Margin }=\frac{\text { Laba Bersih Setelah Pajak }}{\text { Penjualan Bersih }}
$$

Sumber Kasmir (2014)

\section{Return On Equity (ROE)}

Pengertian Return On Equity, menurut Kasmir (2014) : "Hasil investasi pada ekuitas atau Return On Equity atau rentabilitas modal sendiri. 
Rumus ROE adalah sebagai berikut :

$$
\text { Return On Equity }=\frac{\text { Laba Bersih Setelah Pajak }}{\text { Modal Bersih }}
$$

Sumber: Ahmad Rodoni dan Herni Ali (2014)

\section{Earning Per Share (EPS)}

Pendapatan per lembar saham adalah perbandingan yang menunjukan tingkat kemampuan setiap lembar saham dapat memberikan keuntungan (Toto Prihadi.2013).

Vidiati Baru Lestari (2015) Semakin hasil setiap lembar saham suatu perusahaan artinya keuntungan lebih banya yang di dapat dari penempatan saham tersebut. Rumus Earning Per Share adalah sebagai berikut:

\section{Earning Per Share $=\frac{\text { Pendapatan Setelah Pajak }}{\text { Jumlah Saham yang beredar }}$}

Sumber Fahmi (2014)

\section{Kerangka Pemikiran}

Berdasarkan penelitian terdahulu dan tinjauan pustaka, maka hubungan dari setiap variabel variabel dalam hal ini $N P M$, ROE, dan EPS (EPS) terhadap harga saham dituangkan dalam kerangka pemikiran sebagai berikut:

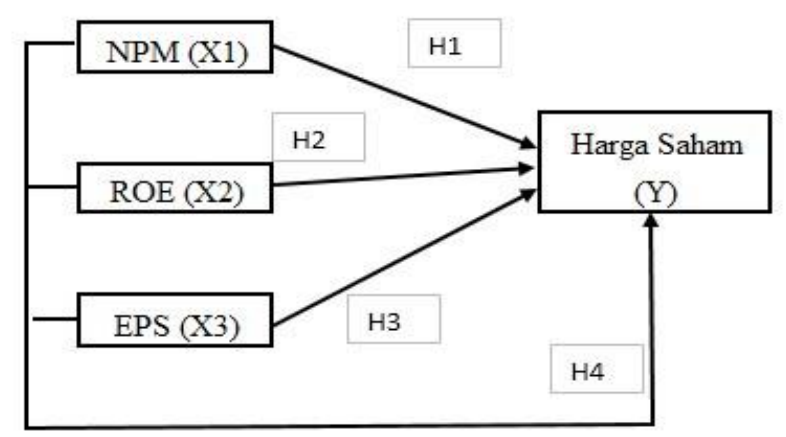

Gambar 1

Model Hubungan Variabel Independen dan Dependen. 
Kerangka pemikiran di atas menggunakan harga saham sebagai variable dependen. Sedangkan variabel independen adalah rasio NPM, ROE, dan EPS guna dilakukan analisis terhadap pengaruh harga saham.

\section{METODE PENELITIAN}

Untuk menganalisis penelitian ini menggunakan Statictical Package for the Sciences Social versi 23.0 Sampel perusahaan yang dipakai adalah perusahaan manufaktur sub sektor industri dasar dan kimia yang sudah Go Publi didaftarkan pada Bursa Efek Indonesia (BEI) sebanyak limabelas perusahaan dalam kurun waktu tahun 2012 - 2016. Dengan menggunakan dari 3(tiga) variabel bebas yaitu Net Profit Margin (NPM), Return On Equity (ROE) dan Earning Per Share (EPS) dengan variable terikat Harga Saham.

\section{Operasionalisasi Variabel Penelitian}

Pokok penelitian disebut Variabel Penelitian (Arikunto 2011). Penggunaan Variabel bebas (X) dan variabel terikat (Y) yang yang digunakan dalam penelitian ini

\section{Variabel Bebas}

Variabel terikat dapat dipengaruhi oleh variabel bebas (Arikunto, 2011) variabel bebas yang dipilih adalah:
a. (X1) sebagai Net Profit Margin (NPM)
b. (X2) sebagai Return On Equity (ROE))
c. (X3) sebagai Earning Per Share (EPS)

\section{Variabel Terikat}

Variabel terikat adalah adalah variabel yang dipengaruhi variabel bebas (Arikunto 2011). Harga Saham (Y) adalah variabel terikat yang digunak dalam penelitian ini.

Berikut (Tabel 2) ini menunjukan tabel operasional variabel bebas dan variabel terikat : 
Tabel 2

Tabel Operasional Variabel Bebas dan Variabel Terikat.

\begin{tabular}{|c|c|c|c|c|}
\hline No. & Variabel & Indokator & Skala & Sumber \\
\hline \multicolumn{5}{|l|}{ A } \\
\hline 1 & $\begin{array}{l}\text { Net Profit Margin } \\
(\mathrm{NPM})\end{array}$ & $N P M=\frac{\text { Laba Bersih Setelah Pajak }}{\text { Penjualan Bersih }}$ & Rasio & $\begin{array}{l}\text { Laporan } \\
\text { Keuangan }\end{array}$ \\
\hline 2 & $\begin{array}{l}\text { Return On Equity } \\
\text { (ROE) }\end{array}$ & $R O E=\frac{\text { Laba Bersih Setelah Pajak }}{\text { Modal Bersih }}$ & Rasio & $\begin{array}{l}\text { Laporan } \\
\text { Keuangan }\end{array}$ \\
\hline 3 & $\begin{array}{l}\text { Earning Per Share } \\
\text { (EPS) }\end{array}$ & $E P S=\frac{\text { Pendapatan Setelah Pajak }}{\text { Jumlah Saham yang beredar }}$ & Rasio & $\begin{array}{l}\text { Laporan } \\
\text { Keuangan }\end{array}$ \\
\hline \multicolumn{5}{|l|}{$\mathrm{B}$} \\
\hline 4 & Harga Saham & Harga Rata-rata Saham per Bulan & Rasio & $\begin{array}{l}\text { Laporan } \\
\text { Keuangan }\end{array}$ \\
\hline
\end{tabular}

Sumber : Kasmir (2014), Ahmad Rodoni dan Herni Ali (2014), Fahmi (2014), Zubir (2011)

\section{Teknik Analisis Data}

Untuk membantu analisis penelitian ini maka digunakan alat bantu program SPSS 23.0 dengan menampilkan bentuk tabulasi agar mudah dimengerti dengan penjelasan deskriptif selanjutnya dilakukan pengolahan data.

\section{Analisis Statistik Deskriptif}

Untuk memperoleh gambaran nilai rata-rata (Mean), standar deviasi, maksimum dan minimum maka digunakan statistik deskriptif merupakan gambaran sebuah infomasi yang lebih jelas dan mudah dipahami. Statistik deskriptif berhubungan dengan pengumpulan data, serta penyajian peningkatan tersebut (Ghozali, 2013)

\section{Uji Asumsi Klasik}

Untuk mengetahui terjadinya ketidak sesuaian yang dilakukan pasca analisa Regresi dan Koefisien Determinasi maka digunakan pengujian Asumsi Klasik. Uji Asumsi Klasik terdiri dari: 


\section{- Uji Normalitas}

Tujuan melakukan Uji normalitas adalah agar bisa mengetahui model regresi, variabel-variabel bebas dan variabel terikat memiliki pembagian yang normal atau mendekati normal (Ghozali, 2013). adalah :

1. Memenuhi asumsi normalitas pada model regresi maka titik harus berserakan disekeliling arah garis diagonal.

2. Jika data tidak berserakan mengikuti garis diagonal maka model regresi persyaratannya belum sesuai dengan asumsi normalitas.

Uji kolmogorovsmirnov digunakan sebagai Uji normalitas lainnya.. Menurut Imam Ghozali (2013) Dengan menbandingkan Z hitung dengan tabel-tabel dengan kriteria distribusi data dapat dilihat sebagai berikut:

a. Distribusi data normal, apabila nilai probalitas > tarif signifikansi 5\% $(0,05)$.

b. Distribusi data tidak normal jika nilai probabilitas < tarif sinifikansi $5 \%$ $(0,05)$.

\section{- Uji Multikolinieritas}

Uji Multikolinieritas dipakai untuk memastikan variabel bebas terjadi Multikolinieritas atau tidak. Teknik korelasi product moment dipakai antar variabel akan menjadi multikolinieritas, jadi nilai interkorelasi antar variabel bebas lebih dari atau sama dengan 0,800, demikian juga sebaliknya. Nilai VIF (Varian Inflation Factor) dan Tolerance pada proses regresi biasa adalah merupakan metode lain dari uji multikolinieritas, jika VIF dan Tolerance hampir pada angka 1 atau besaran VIF tidak lebih dari angka 10 maka Multikolinieritas tidak terjadi mada model ini.

\section{- Uji Heteroskedastisitas}

Untuk mamastikan terjadi ketidaksesuaian variance dari residual suatu penelitian ke penelitian yang lain dalam model regeresi maka digunakan Uji heteroskedastisitas (Ghozali, 2013). Uji Homoskedastisitas jika variabel dari residual suatu pengamatan ke pengamatan lain tetap, dan jika berbeda 
disebut Heteroskedastisitas. Homoskedastisitas atau yang belum terjadi Heteroskedastisitas adalah Model regresi yang baik. Kesalahan yang terjadi pada Heterokedastisitas apabila tidak random (Acak) namun banyaknya satu atau lebih variabel menunjukan hubungan yang sistematis. Dengan menggunakan Uji Glejser maka akan dapat terdeteksi adanya heterokedastisitas dari tingkat signifikasinya. Batas terjadi heterokesdastisitas adalah 5\% jika signifikansi diatas 5\% $(0,05)$ maka dapat dikatakan tidak terjadi gejala heterokedastisitas dan akan terjadi heterokedastisitas jika berada di bawah $5 \%$ (0.05). Untuk menentukan heterokesdastisitas dapat juga menggunakan Grafik Scatterplot, akan terjadi heterokesdastisitas pada model yang digunakan jika titik-titik yang terjadi tidak menyebar dari atas atau di bawah angka 0 pada sumbu $\mathrm{Y}$ demikian sebalik jika menyebar secara acak dibawah 0 pada sumbu Y maka tidak terdapat heterokesdastisitas pada model yang dipakai.

\section{- Uji Autokorelasi}

Suatu model regresi linier ada korelasi antara kesalahan pengguna pada periode $\mathrm{t}$ dengan kesalahan pada periode $\mathrm{t}-1$ maka digunakan Uji Autokorelasi (Ghozali, 2013). Pengamatan terus menerus berkaitan satu sama lain akan muncul Autokorelasi, yang disebabkan oleh residual terikat dari pengamatan ke pengamatan lainnya. Regresi yang bebas dari Autokorelasi adalah model regresi yang baik. Dengan menggunakan Run Test penelitian ini untuk mengetahui ada atau tidaknya autokorelasi karena Run Test adalah merupakan bagian dari statistik non parametrik untuk dimanfaatkan sebagai testing apakah diantara residual masih ada keterkaitan yang tinggi. Residual dinyatakan tidak memiliki hubungan korelasi apabila hasil tes menunjukan tingkat signifikansi lebih dari 0,05 sehingga dapat dikatakan bahwa residual adalah acak atau random (tidak terdapat autokorelasi) (Ghozali, 2013). 


\section{Uji Hipotesis}

Untuk mengetahui pengaruh variabel-variabel yang diteliti maka dilakukan uji hipotesis, dengan mengujikan uji statistik sebagai berikut:

\section{Uji R}

Agar dapat diketahui seberapa kuat hubungan antara varibel-variabel bebas dan variabel terikat maka dilakukan Koefisien korelasi berganda.

Bila $\mathrm{R}=0$ atau mendekati 0 , maka hubungan kedua variable lemah sekali/ terdapat hubungan

Bila $\mathrm{R}=+1$ (positif satu) atau hampir 1 dapat dikatakan keterkaitan variabel bebas dan variabel terikat, positif \& kuat.

Bila $\mathrm{R}=-1$ (Negatif satu) atau menekati -1 maka hubungan variabel bebas dab variabel terikat negatif.

\section{Koefisien Determinasi $\left(\left(\mathbf{R}^{2}\right)\right.$}

Koefisien determinasi (R2) pada intinya melihat manfaat model dalam menginformasikan variasi variabel terikat. Nilai koefisien determinasi adalah antara 0 dan 1. "Nilai R2 yang kecil berarti kemampuan variabelvariabel independen dalam menjelaskan variasi variabel independen amat terbatas. (Imam Ghozali, 2013)"'.

\section{Uji Signifikansi Parsial ( Uji Statistik t)}

Agar dapat diketahui perngaruh satu variabel bebas secara individual dalam menerangkan variasi variabel bebas digunakan Unji Statistik (Ghozali, 2013). Batas angka probabilitas signifikansi $\leq 0.05$ maka hipotesis tidak dapat ditolak karena variabel bebas mempunyai pengaruh signifikan terhadap variabel terikat.

\section{Uji F (Uji Modle)}

Menurut Ghozali (2013), uji statistik F menunjukkan apakah seluruh variabel bebas yang dipakai pada penelitian ini memilik dampak keseluruhan variabel bebas terhadap variabel terikat. Hipotesis nol (H0) 
menandakan bahwa secara keseluruhan atau simultan model ini dinyatakan variabel bebas tidak memiliki pengaruh terhadap varibel terikat, sedangkan

H1 : Menyatakan semua variabel terikat dapat dipenganruhi oleh varibel bebas secara signifikan

H0 : Diterima apabila F hitung $<$ F tabel

H0 : Ditolak apabila F hitung > F tabel

Syarat diterima atau tidak diterima hipotesis adalah sebagai berikut:

1. Regresi dapat dipakai lebih lanjut pada uji hipotesis ini seandainya nilai signifikansi lebih kecil dari 0,05 (signifikansi < 0,05)

2. Regresi tidak akan dipakai untuk uji hipotesis jika nilai signifikansi melebihi angka 0,05 ( signifikansi > 0,05)

\section{HASIL PENELITIAN DAN PEMBAHASAN}

Data yang dipakai untuk melakukan hal ini adalah laporan keuangan perusahaan terbuka sub sektor insdustri dasar dan kimia tahun 2012 sampai dengan tahun 2016 yang diunduh dari www.idx.co.id.

Penelitian ini menggunakan dari 3(tiga) variabel bebas yaitu NPM, RO dan EPS dengan variable terikat Harga Saham. Yang dijadikan sampel adalah 15 (lima belas) perusahaan manufaktur sub sektor industri dasar dan kimia yang sudah Go Public dan didaftarkan pada Bursa Efek Indonesia (BEI) pada periode tahun 2012 - 2016 dengan variabel analisis adalah NPM, ROE, EPS dan Harga Saham.

\section{Uji Asumsi Klasik}

Pengertian Uji Asumsi Klasik, menurut Ramadhina (2011) : Uji asumsi klasik untuk memastikan prakiraan regresi yang dilaksanakan harus bebas dari tanda tanda terjadinya heterokedastisitas, sinyal terjadinya multikolonieritas dan gejala autokorelasi serta normalitas.

\section{Uji Normalitas}

Menurut Ghozali (2013): Uji normalitas adalah untuk mengetahui apakah model regresi, variabel pengganggu atau residual memiliki distribusi normal. Pada penelitian ini digunakan Uji t untuk mengasumsikan bahwa 
angka-angka residual menyertai distribusi normal. Uji statistik akan tidak valid untuk jumlah sampel yang sedikit oleh karena asumsi itu tidak digunakan. Untuk mengetahui prakiraan residual berdistribusi wajar atau tidak wajar, ada dua cara yaitu dengan analisis grafik (Histogram dan Normal P-P plot) dan uji statistik (Uji One Sample Kolmogorov-Smirnov).

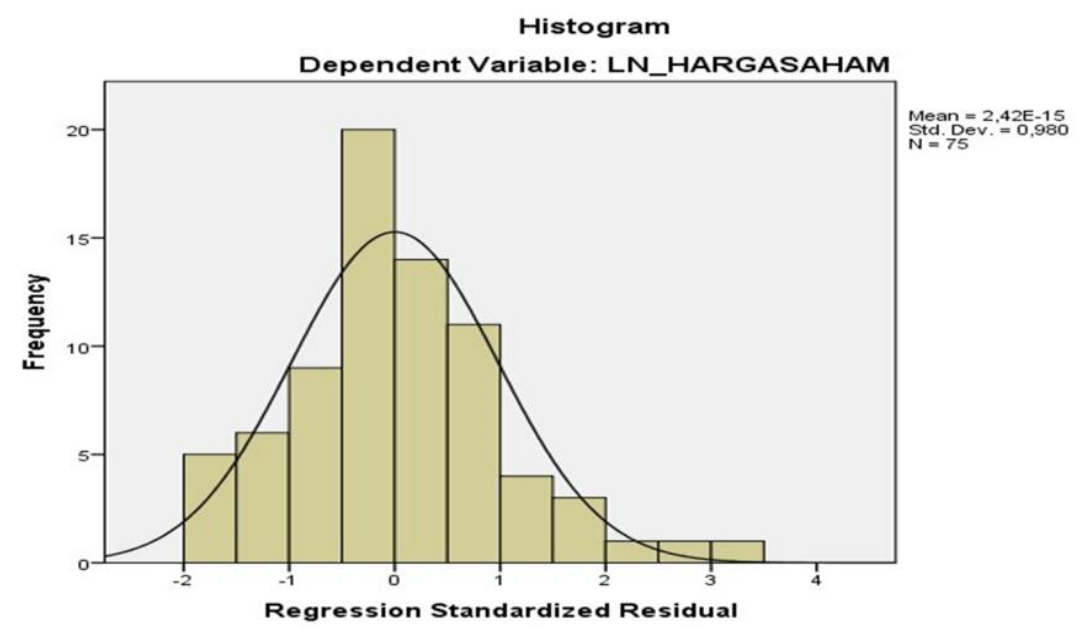

Sumber : Pengolahan Data dengan SPSS Version 23

\section{Gambar 2}

\section{Histogram Normalitas}

Berdasarkan sebaran data pada grafik histogram terlihat membentuk lonceng, tidak condong ke kiri atau ke kanan. Sehingga dapat dinyatakan data berdistribusi normal atau model regresi memenuhi asumsi normalitas.

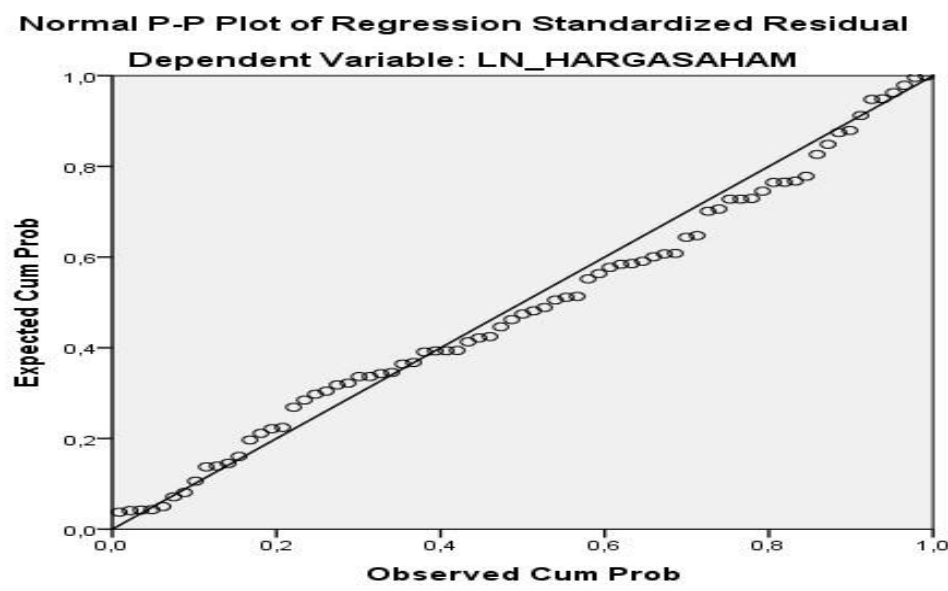

Sumber : Pengolahan Data dengan SPSS Version 23

Gambar 3

Normal P-P Plot 
Dari gambar 3 terlihat data tersalurkan dengan wajar dan model regresi telah sesuai dengan asumsi normalitas atau dapat dijadikan materi dalam penelitian ini sebab pada garis diagonal diikuti dengan data yang menyebar disekitarnya.

Tabel 3

One-Sample Kolmogorov-Smirnov Test

\begin{tabular}{|ll|r|}
\hline & & $\begin{array}{c}\text { Unstandardized } \\
\text { Residual }\end{array}$ \\
\hline Normal Parameters ${ }^{\mathrm{a}, \mathrm{b}}$ & Mean & 75 \\
& Std. Deviation &, 0000000 \\
Most Extreme Differences & Absolute & 13458238 \\
& Positive &, 083 \\
& Negative &, 083 \\
Test Statistic & & - \\
& &, 05 \\
& & 4 \\
& & 3 \\
Asymp. Sig. (2-tailed) &, $200^{\mathrm{c}, \mathrm{d}}$ \\
\hline
\end{tabular}

a. Test distribution is Normal.

b. Calculated from data.

c. Lilliefors Significance Correction.

d. This is a lower bound of the true significance.

Sumber : Pengolahan Data dengan SPSS Version 23

Hasi tabel one Sample Kolmogorov-Smirnov Test nilai signifikansi angka 0,200 lebih besar dari 0,05. artinya residual berdistribusi normal.

\section{Uji Multikolinearitas}

"Uji multikolinearitas bertujuan untuk membuktikan atau menguji ada tidaknya hubungan linier antar variabel bebas atau independen antar satu dengan variabel bebas lainnya" (Ramadhina,2012). Jika semakin besar VIF dan nilai Tolerance semakin kecil maka akan mendekati terjadinya masalah multikolinearitas. Dengan melihat nilai Tolerance dan VIF akan terlihat ada tidaknya multikolinearitas. Multikolinearitas tidak akan ada jika Tolerance melebihi 0,1 dan VIF tidak lebih dari 10. 
Tabel 4

Uji multikolinearitas

Coefficients $^{\mathrm{a}}$

\begin{tabular}{|c|c|c|c|c|c|c|c|c|}
\hline \multirow[b]{2}{*}{ Model } & & \multicolumn{2}{|c|}{$\begin{array}{l}\text { Unstandardized } \\
\text { Coefficients }\end{array}$} & \multirow{2}{*}{\begin{tabular}{|c|} 
Standardized \\
Coefficients \\
Beta
\end{tabular}} & \multirow[b]{2}{*}{$\mathrm{t}$} & \multirow[b]{2}{*}{ Sig. } & \multicolumn{2}{|c|}{ Collinearity Statistics } \\
\hline & & B & Std. Error & & & & Tolerance & VIF \\
\hline 1 & (Constant) & 5,830 &, 145 & & 40,312 &, 000 & & \\
\hline & NPM & ,004 & ,013 & ,037 & $\begin{array}{l}, 322 \\
1470\end{array}$ & ,748 & 669 & 1,494 \\
\hline & $\begin{array}{l}\text { ROE } \\
\text { EPS }\end{array}$ & ,011 & ,008 & ,165 & $\begin{array}{l}1,4 / 0 \\
5,004\end{array}$ & , 146 & ,712 & 1,404 \\
\hline & & ,003 & ,001 &, 513 & & ,000 & 857 & 1,167 \\
\hline
\end{tabular}

a. Dependent Variable: LN_HARGASAHAM

Sumber : Pengolahan Data dengan SPSS Version 23

Berdasarkan tabel 4 , dapat dilihat bahwa nilai Tolerance variabel bebas $N P M$ lebih dari 0,1 yaitu 0,669 sedangkan $R O E$ lebih dari 0,1 yaitu 0,712 sedangkan EPS lebih dari 0,1 yaitu 0,857 dan nilai Variance Inflation Factor (VIF) kurang dari 10 yaitu 1,494 untuk NPM dan nilai Variance Inflation Factor (VIF) kurang dari 10 yaitu 1,404 untuk ROE sedangkan EPS kurang dari 10 yaitu 1,167. Artinya bahwa variabel bebas NPM, ROE, dan EPS tidak terjadi masalah multikolinearitas dan dapat digunakan sebagai data penelitian.

\section{Uji Heterokedastisitas}

Menurut Ghozali (2013) untuk mendeteksi ada atau tidaknya heteroskedastisitas dari suatu analisis adalah :

1. Heterokedastistas terjadi apabila titik-titik menjadi pola tertentu (melebar, bergelombang dan menyempit),

2. Heterokedastisitas tidak terjadi seandainya titik-titik berserakan tidak teratur diantara bawah angka 0 pada sumbu Y. 


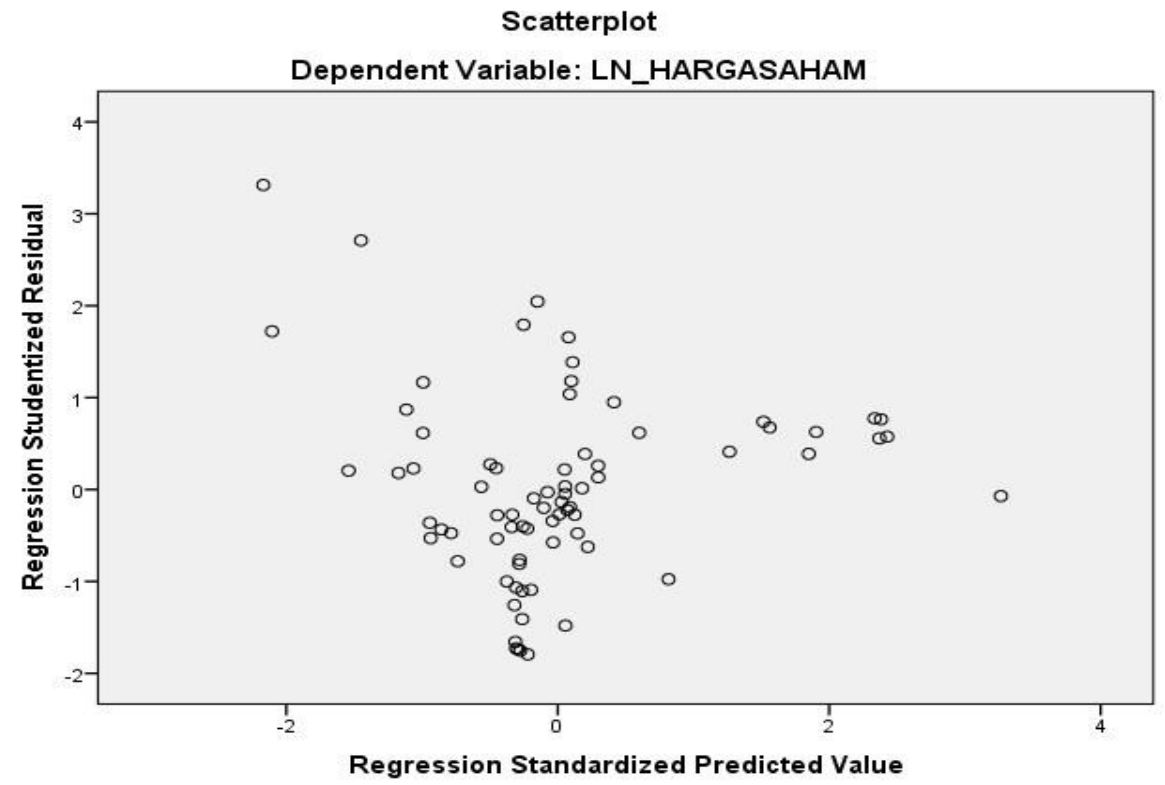

Sumber : Pengolahan Data dengan SPSS Version 23

Gambar 4

Uji heteroskedastisitas

Dari gambar 4 terlihat tidak terjadi heterokedastisitas pada model regresi karena titik-titik berkumpul dan berserakan tanpa pola yang jelas di bawah angka 0 pada sumbu Y, sehingga model regresi layak dipergunakan. Selain grafik scatterplot, heteroskedastisitas dapat menggunakan uji Spearman rho dengan menghubungkan nilai residual (unstandardixzed residual) dari setiap variabel bebas. "Jika nilai signifikansi antara variabel independen dengan nilai residual lebih dari 0,05 maka tidak terjadi masalah heteroskedastisitas (Priyatno, 2016)". 
Tabel 5

Uji Spearman's rho

\section{Correlations}

\begin{tabular}{|c|c|c|c|c|c|c|}
\hline & & & NPM & ROE & EPS & $\begin{array}{l}\text { LN_HARGA } \\
\text { SAHAM }\end{array}$ \\
\hline \multirow{12}{*}{$\begin{array}{l}\text { Spearman's } \\
\text { rho }\end{array}$} & NPM & Correlation Coefficient & 1,000 &, $869^{* *}$ &, $552^{* *}$ &,- 107 \\
\hline & & Sig. (2-tailed) & . &, 000 &, 000 & ,459 \\
\hline & & $\mathrm{N}$ & 75 & 75 & 75 & 75 \\
\hline & ROE & Correlation Coefficient &, $869^{* *}$ & 1,000 &, $561^{* *}$ & 009 \\
\hline & & Sig. (2-tailed) &, 000 & &, 000 & ,952 \\
\hline & & $\mathrm{N}$ & 75 & 75 & 75 & 75 \\
\hline & EPS & Correlation Coefficient &, $552^{* *}$ &, $561^{* *}$ & 1,000 &, $305^{*}$ \\
\hline & & Sig. (2-tailed) &, 000 &, 000 & &, 031 \\
\hline & & $\mathrm{N}$ & 75 & 75 & 75 & 75 \\
\hline & LN_HARGA & Correlation Coefficient &,- 107 &, 009 &, $305^{*}$ & 1,000 \\
\hline & SAHAM & Sig. (2-tailed) & ,459 & ,952 &, 031 & \\
\hline & & $\mathrm{N}$ & 75 & 75 & 75 & 75 \\
\hline
\end{tabular}

**. Correlation is significant at the 0.01 level (2-tailed).

*. Correlation is significant at the 0.05 level (2-tailed).

Sumber : Output SPSS Versi 23

Berdasarkan Tabel 5 diatas, hasil uji spearmans rho nampak nilai signifikansi setiap variabel $N P M$ pada angka $0,459, R O E$ pada angka 0,952 , dan EPS pada angka 0,31. Dari ketiga variabel bebas tersebut memiliki nilai signifikansi $>0,05$ sehingga dapat dikatakan heterokedastisitas tidak terjadi pada model regresi penelitian ini.

\section{Uji Autokorelasi}

Pengujian autokorelasi dilakukan untuk mengetahui apakah persamaan regresi mempunyai masalah autokorelasi atau tidak. Run Test digunakan dalam penelitian ini dan uji autokorelasi dilakukan dengan menggunakan sebagai berikut: 
1. Menentukan hipotesis alternatif dan dan hipotesis nol

- Ho : Tidak adal autokorelasi apabila residual random (acak).

- Ha : Terdapat autokorelasi apabila residual tidak random.

2. Tingkat keyakinan interval akan signifikan $\alpha=0,05$ atau taraf signifikansi $5 \%$

3. Hasil Pengujian autokorelasi Run Test dengan menggunakan SPSS sebagai berikut:

\section{Tabel 6 \\ Runs Test}

\begin{tabular}{|l|r|}
\hline & $\begin{array}{c}\text { Unstandardized } \\
\text { Residual }\end{array}$ \\
\cline { 1 - 1 } Test Value $^{\mathrm{a}}$ &,- 07409 \\
Cases < Test Value & 37 \\
Cases >= Test Value & 38 \\
Total Cases & 75 \\
Number of Runs & 33 \\
Z & $-1,278$ \\
Asymp. Sig. (2-tailed) &, 201 \\
\hline
\end{tabular}

a. Median

Sumber : Pengolahan Data dengan SPSS Version 23

Dari tabel tersebut diatas terlihat hasil uji autokorelasi dengan Run Test dengan menggunakan SPSS 23.0 menunjukkan nilai probabilitas 0,201 artinya 0,05 $(0,201>0,05)$, Sehingga Ho diterima dan Ha tidak dapat diterima dapat dikatakan residual random tidak terdapat autokorelasi.

\section{Analisis Koefisien Korelasi}

"Analisis korelasi bertujuan untuk mengetahui hubungan dua variabel atau lebih. 
Tabel 7

Pedoman Koefisien Korelasi

\begin{tabular}{|c|c|}
\hline Batas Koefisien & Nilai Hubungan Keterkaitan \\
\hline 0 & Tidak ada keterkaitan antar dua variabel \\
\hline $0-0,25$ & Hubungan Keterkaitan sangat lemah \\
\hline $0,25-0,5$ & Hubungan Keterkaitan cukup \\
\hline $0,5-0,75$ & Hubungan Keterkaitan kuat \\
\hline $0,75-0,99$ & Hubungan Keterkaitan sangat kuat \\
\hline 1 & Hubungan Keterkaitan sempurna \\
\hline
\end{tabular}

Sumber: (Ramadhina, 2015)

Dalam penelitian ini korelasi variabel tersebut terlihat dari tabel 8 berikut:

\section{Tabel 8}

\section{Correlations}

\begin{tabular}{|c|c|c|c|c|c|}
\hline & & NPM & ROE & EPS & $\begin{array}{c}\text { LN_HARGA } \\
\text { SAHAM }\end{array}$ \\
\hline NPM & Pearson Correlation & 1 &, $529^{* *}$ &, $364^{* *}$ &, $312^{* *}$ \\
\hline & Sig. (2-tailed) & & ,000 & 00175 &, 006 \\
\hline & $\mathrm{N}$ & 75 & 75 & & 75 \\
\hline ROE & Pearson Correlation &, $529^{* * *}$ & 1 & $278^{*}$ &, $328^{* *}$ \\
\hline & Sig. (2-tailed) &, 000 & & 01675 &, 004 \\
\hline & $\mathrm{N}$ & 75 & 75 & & 75 \\
\hline EPS & Pearson Correlation &, $364^{* * *}$ & ,278* & 1 &, $573^{* *}$ \\
\hline & Sig. (2-tailed) &, 001 &, 016 & &, 000 \\
\hline & $\mathrm{N}$ & 75 & 75 & 75 & 75 \\
\hline LN_H & Pearson Correlation &, $312^{* *}$ &, $328^{* *}$ &, $573^{* * *}$ & 1 \\
\hline AHAN & Sig. (2-tailed) & ,006 & ,004 & 00075 & \\
\hline & $\mathrm{N}$ & 75 & 75 & & 75 \\
\hline
\end{tabular}

**. Correlation is significant at the 0.01 level (2-tailed).

*. Correlation is significant at the 0.05 level (2-tailed).

Sumber : Pengolahan Data dengan SPSS Version 23

Berdasarkan tabel Correlations dapat diketahui hubungan keterkaitan setiap variabel bebas terhadap variabel terikat sebagai berikut :

\section{a. Korelasi antara NPM dengan Harga Saham}

Angka korelasi sebesar 0,312 ini berarti variabel NPM berhubungan cukup baik dengan arah hubungan positif, yaitu apabila 
$N P M$ naik maka harga saham akan terpengaruh naik. Antara NPM dan harga saham terdapat tingkat signifikan sebesar 0,006 artinya terdapat hubungan korelasi positif dan signifikan antara NPM dengan harga saham hal ini disebabkan karena nilai Sig. Sebesar 0,006 <0,05.

\section{b. Korelasi antara $R O E$ dengan Harga Saham}

Nilai korelasi menunjukkan sebesar 0,328 ini berarti variabel $R O E$ memiliki hubungan cukup baik dengan arah hubungan positif, yaitu jika $R O E$ naik maka akan mempengarui harga saham menjadi naik. Hubungan $R O E$ dengan harga saham dengan tingkat signifikan sebesar 0,004 yang menunjukkan bahwa terdapat hubungan korelasi yang signifikan antara $R O E$ dengan harga saham karena nilai Sig. Sebesar $0,004<0,05$. Sehingga hasil penelitian ini menunjukkan bahwa hubungan korelasi $R O E$ terjadi dengan cukup baik sesuai dengan arah hubungan positif.

\section{c. Korelasi antara EPS dengan Harga Saham}

Nilai korelasi menunjukkan sebesar 0,573 ini berarti variabel EPS berhubungan kuat dengan arah hubungan positif, yaitu apabila EPS naik maka akan mempengaruhi harga saham sehingga akan ikut naik dan apabila EPS turun maka akan berpengaruh terhadap harga saham dan ikut turun pula. Hubungan EPS dengan harga saham dengan tingkat signifikan sebesar 0,000 yang menunjukkan bahwa terjadi hubungan korelasi positif dan signifikan saling mempengaruhi hubungan antara nilai EPS dengan harga saham karena nilai Sig. Sebesar 0,000 $<0,05$. Penelitian ini menandakan bahwa EPS memiliki hubungan kuat dan saling mempengaruhi dengan arah hubungan positif.

\section{Analisis Koefisien Determinasi $\left(\mathbf{R}^{2}\right)$}

Menurut Priyanto (2013) : Seberapa besar \% sumbangan pengaruh variabel bebas secara serentak terhadap variabel terikat dapat menggunakan Analisis koefisien determinasi $\left(\mathrm{R}^{2}\right)$. Pada Output Model 
Summary dapat diketahui perhitungan $R$ Square, dan pada kolom $R$ Square diketahui presentase dibuktikan dengan terjadinya setiap variabel bebas terhadap variabel terikat. Dan selebihnya tidak dipakai dalam model penelitian.

\section{Tabel 9}

\section{Analisis Koefisien Determinasi}

\begin{tabular}{|l|r|r|r|c|}
\hline Model & $\mathrm{R}$ & R Square & $\begin{array}{c}\text { Adjusted R } \\
\text { Square }\end{array}$ & $\begin{array}{c}\text { Std. Error of the } \\
\text { Estimate }\end{array}$ \\
\hline 1 &, $600^{\mathrm{a}}$ &, 360 &, 333 & 1,15830 \\
\hline
\end{tabular}

a. Predictors: (Constant), EPS, ROE, NPM

b. Dependent Variable: LN_HARGASAHAM

Sumber : Pengolahan Data dengan SPSS Version 23

Berdasarkan tabel 9 dapat diketahui nilai $\mathrm{R}^{2}$ ( $R$ Square) adalah 0,360 atau 36\% Artinya NPM, ROE, dan EPS dapat mempengaruhi Harga Saham sebesar 36\%. selebihnya sebesar 64\% (100\%-36\%) dapat dipengaruhi oleh faktor variabel dari bukan penelitian ini.

\section{Analisis Regresi Linier Berganda}

Menurut Ramadhina (2015) : analisis regresi dapat melihat keterkaitan variabel bebas kepada variabel terikat dan juga memperkirakan variabel terikat. Uji regresi berganda terdiri dari satu variabel terikat (Y) dan terdiri dari dua atau lebih variabel bebas $(\mathrm{X})$.

Model regresi: $\mathrm{Y}=\mathrm{a}+\mathrm{b} 1 \mathrm{X} 1+\mathrm{b} 2 \mathrm{X} 2+\mathrm{b} 3 \mathrm{X} 3+\mathrm{b} 4 \mathrm{X} 4$

Keterangan:

$\mathrm{Y}=$ = Nilai prediksi variabel terikat

a $\quad=$ Konstanta, yaitu nilai $Y^{\prime}$ jika X1, X2, X3, X4 = 0

b1 - b4 = Koefisien regresi, yaitu nilai peningkatan atau penurunan variabel Y' didasarkan variabel X1, X2, X3, X4 = Variabel bebas 
Tabel 10

Uji Regresi Linier Berganda

\section{Coefficients $^{\mathrm{a}}$}

\begin{tabular}{|c|c|c|c|c|c|c|c|}
\hline \multirow[b]{2}{*}{ Model } & \multicolumn{2}{|c|}{$\begin{array}{c}\text { Unstandardized } \\
\text { Coefficients }\end{array}$} & \multirow{2}{*}{$\begin{array}{c}\text { Standardized } \\
\text { Coefficients } \\
\text { Beta }\end{array}$} & \multirow[b]{2}{*}{$\mathrm{t}$} & \multirow[b]{2}{*}{ Sig. } & \multicolumn{2}{|c|}{$\begin{array}{l}\text { Collinearity } \\
\text { Statistics }\end{array}$} \\
\hline & B & Std. Error & & & & Tolerance & VIF \\
\hline 1 (Constant) & 5,830 &, 145 & & 40,312 &, 000 & & \\
\hline NPM & ,004 & ,013 & ,037 & ,322 & ,748 & ,669 & 1,494 \\
\hline ROE & ,011 & ,008 & , 165 & 1,470 &, 146 & ,712 & 1,404 \\
\hline EPS & ,003 & ,001 &, 513 & 5,004 & ,000 & ,857 & 1,167 \\
\hline
\end{tabular}

a. Dependent Variable: LN_HARGASAHAM

Sumber : Pengolahan Data dengan SPSS Version 23

Berdasarkan tabel 10 Uji Regresi Linier Berganda dapat ditarik kesimpulan bahwa koefisien regresi antara Harga Saham yang merupakan variabel terikat dapat dipengaruhi oleh variabel bebas sehingga persamaan regresi linier berganda yaitu :

Harga Saham $=5,830$ + 0,04 NPM X1 + 0,11 ROE X2 + 0,003 EPS X3

Keterangan:

NPM X1 :NPM

ROE X2 : ROE

EPS X3 : EPS

Persamaan regresi linier berganda di atas dapat diinterpretasikan sebagai berikut:

a. Konstanta: 5,830, Artinya apabila $N P M \mathrm{X}_{1}, R O E \mathrm{X}_{2}$, dan $E P S \mathrm{X}_{3}$ bernilai 0 maka Harga Saham sebesar 5,830.

b. Koefisien regresi variabel $N P M \mathrm{X}_{1}$ : 0,04, Artinya jika $R O E \mathrm{X}_{2}$, dan $E P S$ $\mathrm{X} 3$ nilainya 0 dan jika $N P M \mathrm{X}_{1}$ terjadi kenaikan 1 satuan (\%), jadi nilai Saham (Y) akan terjadi kenaikan senilai 0,04 satuan (\%).

c. Koefisien regresi variabel $R O E \mathrm{X}_{2}$ sebesar 0,11 artinya variabel bebas angkanya tetap dan $R O E$ naik 1 satuan (\%), maka harga saham (Y) akan 
naik sebesar 0,11 satuan (\%). Menurut Muhammad Dicky (2016): Koefisien positif antara variabel bebas dengan variabel terikat.

d. Koefisien regresi variabel EPS X3 sebesar ,003 Variabel bebas angkanya tetap dan EPS naik 1 satuan, jadi nilai saham (Y) naik 0,003 satuan. Koefisien bernilai positif antara variabel bebas dengan variabel terikat, jika EPS naik maka dividen juga akan naik.

\section{Uji Hipotesis}

\section{Uji F (Goodness of Fit Test)}

Menurut Rochaety, Tresnati, dan Latief (2009) Uji F (Tabel ANOVA) dipakai untuk melihat apakah model regresi bisa digunakan dalam penelitian ini, dengan cara membandingkan tarif signifikansi (sig) hitung dengan 0,05 (5\%). Ho diterima dan $\mathrm{H} \alpha$ ditolak jika probabilitas (sig penelitian) $>0,05$.

- Ho ditolak dan Ha dipakai sebab probabilitas (sig penelitian) <0,05.

Tabel 11

Uji F (Goodness of Fit Test)

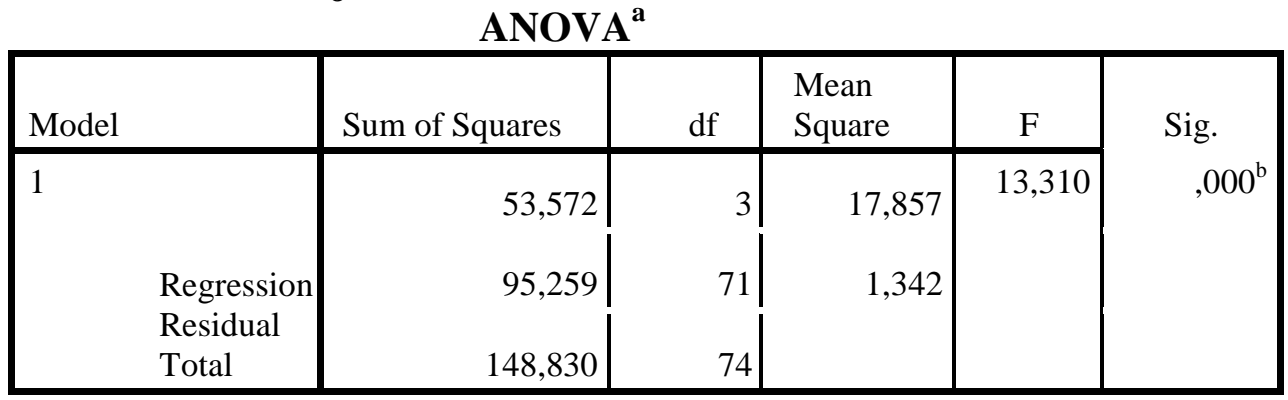

a. Dependent Variable: LN_HARGASAHAM

b. Predictors: (Constant), EPS, ROE, NPM

Sumber : Pengolahan Data dengan SPSS Version 23

Berdasarkan output pada tabel 11 diperoleh angka signifikansi senilai $0,000<0,05$ maka nilai Ho tidak dapat diterima dan nilai $\mathrm{H} \alpha$ tidak ditolak. Hal ini berarti model regresi layak sudah dapat digunakan dalam penelitian ini. 


\section{Uji t}

"Uji t dilakukan untuk mengetahui pengaruh variabel bebas individual terhadap variabel terikat, apakah pengaruhnya signifikan atau tidak (Priyanto, 2013)". Pengambilan keputuasan ini dengan menggunakan signifikansinya adalah:

1. Ho diterima apabila nilai signifikansi $>0,05$

2. Ho tidak diterima apabila nilai signifikansi $<0,05$

\section{Tabel 12}

Uji t

\section{Coefficients $^{\mathrm{a}}$}

\begin{tabular}{|c|c|c|c|c|c|c|c|}
\hline \multirow[b]{2}{*}{ Model } & \multicolumn{2}{|c|}{$\begin{array}{l}\text { Unstandardized } \\
\text { Coefficients }\end{array}$} & \multirow{2}{*}{$\begin{array}{c}\text { Standardize d } \\
\text { Coefficients } \\
\text { Beta }\end{array}$} & \multirow[b]{2}{*}{$\mathrm{t}$} & \multirow[b]{2}{*}{ Sig. } & \multicolumn{2}{|c|}{ Collinearity Statistics } \\
\hline & $\mathrm{B}$ & Std. Error & & & & Tolerance & VIF \\
\hline 1 (Constant) & 5,830 &, 145 & & 40,312 &, 000 & & \\
\hline NPM & ,004 & ,013 & ,037 & ,322 & ,748 & 669 & 1,494 \\
\hline EPS &, 011 & ,008 & , 165 & 1,470 & , 146 & ,712 & 1,404 \\
\hline & ,003 & ,001 & ,513 & 5,004 & ,000 & 857 & 1,167 \\
\hline
\end{tabular}

a. Dependent Variable: LN_HARGASAHAM

Sumber : Pengolahan Data dengan SPSS Version 23

Dari tabel 12 menggambarkan hal-hal yaitu:

1. Observasi menghasilkan Ho diterima $\mathrm{H} 1$ ditolak karena nilai signifikansi variabel bebas NPM sebesar 0,748 lebih besar dari 0,05 $(0,748>0,05)$. Sehingga variabel terikat harga saham tidak dapat dipengaruhi dengan $N P M$

2. Hasil pengujian menunjukkan Ho diterima $\mathrm{H} 2$ ditolak karena memiliki nilai signifikansi variabel bebas $R O E$ sebesar 0,146 lebih besar dari 0,05 $(0,146>0,05)$. Sehingga variabel terikat harga saham tidak dipengaruhi oleh variabel bebas $R O E$.

3. Hasil pengujian menunjukkan Ho ditolak H3 diterima karena nilai signifikansi variabel bebas EPS sebesar 0,000 lebih kecil dari 0,05 $(0,472<0,05)$. Sehingga dapat disimpulkan Variabel terikat Harga 
Saham dapat dipengaruhi secara signifikan oleh Variabel Bebas harga per lembar saham (EPS).

\section{Rangkuman Hipotesis}

Interpretasi hasil penelitian berikut adalah merupakan rangkuman hipotesis penelitian yang menunjukkan variabel bebas yang dapat mempengaruhi secara signifikan dan tidak memiliki pengaruh signifikan terhadap variabel terikat variabel terikat :

Tabel 13

Rangkuman Hipotesis

\begin{tabular}{|l|c|c|c|}
\hline $\begin{array}{c}\text { Variabel Independen } \\
\text { (X) }\end{array}$ & $\begin{array}{c}\text { Ada } \\
\text { Pengaruh } \\
\text { Signifikan }\end{array}$ & $\begin{array}{c}\text { Tidak Ada } \\
\text { Pengaruh } \\
\text { Signifikan }\end{array}$ & $\begin{array}{c}\text { Variabel } \\
\text { Dependen (Y) }\end{array}$ \\
\hline Net Profit Margin (X1) & & $\sqrt{ }$ & Harga Saham \\
\hline Return On Equity (X2) & & $\sqrt{ }$ & Harga Saham \\
\hline Earning Per Share (X3) & $\sqrt{ }$ & & Harga Saham \\
\hline
\end{tabular}

\section{KESIMPULAN}

Penggunaan analisis regresi linier berganda dan program bantu SPSS 23.0 dari penelitian ini menghasilkan, sebagai berikut:

1. Variabel terikat harga saham tidak dapat dipengarui oleh variabel bebas $N P M$.

2. Variabel terikat harga saham tidak dapat dipengarui oleh variabel bebas ROE.

3. Variabel terikat Nilai Saham dipasar sangar dapat dipengaruhi oleh variabel bebas EPS dengan signifikan.

\section{REFERENSI}

Arikunto, Suharsimi. 2011. Prosedur Penelitian Suatu Pendekatan Praktek. Jakarta : PT. Rineka Citra.

Darmadji, Tjiptono, dan Hendy M. Fakhruddin. 2011. Pasar Modal Di Indonesia. Jakarta: Salemba Empat. 
Ety, Rochaet, Ratih Tresnati, Abdul Madjid Latief. 2009. Metode Penelitian Bisnis Dengan Aplikasi SPSS. Jakarta: Mitra Wancana Media.

Ghozali, Imam. 2013. Aplikasi Analisis Miltivirate Dengan Program IBM SPSS

21 Update PLS Regresi Edisi 7. Cetakan ke-7. Semarang: BP Universitas Diponegoro.

Harahap, Sofyan Syafri. 2015. Analisis Kritis atas Laporan Keuangan. Edisi 110. Jakarta: Rajawali Pers.

Indriantoro, Nur., et all. 2009. Metodologi Penelitian Akuntasi dan Manajemen.

Edisi Pertama, Cetakan Kedua. Yogyakarta: BPFE.

Irham, Fahmi. 2014. Analisis Laporan Keuangan. Bandung : Alfabeta

Kasmir. 2014. Analisis Laporan Keungan. Jakarta: PT. Rajagrafindo Persada

Laporan Keuangan Perusahaan Tercatat , 2016, http://www.idx.co.id/ diakses 13 Desember 2017.

Prihadi, Toto. 2013. Analisis Laporan Keuangan : Teori dan Aplikasi. Cetakan ke-3. Jakarta ,PPM.

Rodoni, et al. 2014. Manajemen Keuangan Modern. Edisi Asli. Jakarta : Mitra Wacana Media

Rusdin. 2008. Pasar Modal. Cetakan Kedua. Bandung: Alfabeta.

Samsul, Mohammad. (2015). Pasar Modal dan Manajemen Portofolio.Edisi kedua Jakarta: Erlangga.

Sartono. Agus. 2010. Manajemen Keuangan Teori dan Aplikasi. . Yogyakarta: BPEF-YOGYAKARTA.

Singgih, Santoso. 2012. Aplikasi SPSS Pada Statistik Parametik, Edisi 1. Jakarta: Liberty, Yogyakarta.

Sugiyono. 2010. Metode Penelitian Kuantitatif Kualitatif dan R\&D. Bandung Alfabeta.

Sukmadinata, Nana Syaodih. 2013. Metode Penelitian Pendidikan. Bandung : PT Remaja Rosdakarya

Sunariyah. 2010. Pengantar Pengetahuan Pasar Modal. Edisi kelima, Yogyakarta: AMP YKPN. 
Tandelilin Eduardus, 2010. Portofolio dan Investasi, Teori dan Aplikasi, Penerbit Kanisius (Anggota IKAPI) Yogyakarta.

Zubir. 2011. Manajemen Portofolio Penerapannya Dalam Investasi Saham. Jakarta : Salemba Empat. 